\title{
Advance care planning in healthy older adults
}

\author{
Karen Van Leuven \\ University of San Francisco
}

\begin{abstract}
This article reports the secondary analysis of a qualitative study that examined the beliefs, values, lifestyles and health status of adults at least 75 years old $(\mathrm{N}=18)$. An unanticipated finding was that all participants who self-identified as healthy $(\mathrm{N}=14)$ had in place advance directives which dictated their end-of-life wishes. In contrast, participants who self-identified as fair or poor health $(\mathrm{N}=4)$ did not have advance directives $(\mathrm{N}=4)$. These "healthy" older adults also differed substantially from their counterparts in the degree in which they were socially engaged in their community and family, but varied little related to their actual medical diagnoses or health problems. The self-described healthy group approached advanced care planning as part of health promotion; they simultaneously planned for end-of-life while engaging in activities to maintain optimum health. In contrast, those who evaluated their health as fair or poor perceived advanced care planning as something to be avoided. Planning for end-of-life may be a form of ongoing engagement as it requires dialogue with health care providers, and thoughtful consideration of experiences and wishes. It may also be a manifestation of successful aging in that death is recognized as the culmination of a good life rather than something to be feared.
\end{abstract}

(C) 2011 Californian Journal of Health Promotion. All rights reserved.

Keywords: advance directives, older adults, social engagement, successful aging

\section{Introduction}

Successful aging is an important concept given the trend toward increased longevity. On the surface, it might appear that successful aging would be synonymous with being healthy in older adulthood. However, it appears to be a complex construct that may also include attitudes toward end-of-life. This article will explore the findings of related research, and report on an unanticipated finding surrounding advance directives in a qualitative study involving older adults who self identify as healthy.

\section{Literature Review}

Currently there is little agreement about what constitutes successful aging (Depp \& Jeste, 2009; Lupien \& Wan, 2004; McLaughlin, Connell, Heeringa, Li, \& Roberts, 2010). Pressey \& Simcoe (1950) began work in the field through an investigation of case comparisons of older adults who successfully age versus those who experience problems with aging. They determined that varied interests, activities, and continued usefulness to others were essential for successful aging. However, the field did not flourish until a decisive publication by Rowe \& Kahn (1987) postulated that aging and disease are often confounded and that successful aging involves little or no physiological decline. In 1997, Rowe \& Kahn amended their definition of successful aging to include three components: low probability of disease and disease-related disability, high cognitive and physiological functional capacity, and active engagement with life. This definition has been the prevailing model used in research on successful aging.

In 2002 Strawbridge, Wallhagen \& Cohen conducted a study evaluating Rowe \& Kahn's definition of successful aging among 867 respondents 65-99 years of age from Alameda County, California. They found significant numbers of people lacking chronic health 
problems or functional limitations rated themselves in poor health and aging poorly, while numerous individuals with chronic health problems and resultant deficits, viewed themselves as healthy and aging successfully. However, they did not investigate level of engagement. Based on the findings, Strawbridge, Wallhagen \& Cohen (2002) recommended further study employing qualitative interviews with older adults to identify how successful aging is operationalized by individuals.

Other researchers have postulated that successful aging involves achieving a positive balance between gains and loses that occur through the lifespan (Baltes, 1997; Schulz \& HeckHausen, 1996), successful adaptation to changes that occur with aging (von Faber et al., 2001), and avoiding disease until very late in life (Fries, 2002). More recently, there has been interest in exploring the perspective of older adults. Phelan, Anderson, LaCroix \& Larson (2004) compared older adults' views versus researchers' views on successful aging. Using large samples of community-based, non-demented, mostly college-educated, Caucasian $(\mathrm{N}=2581)$ and Japanese-American $(\mathrm{N}=1,985)$ older adults, Phelan et al. (2004) determined that older adults have a multidimensional view of successful aging that encompasses physical, psychological, functional and social domains. Social health was perceived as the most important component. The two highest rated items related to successful aging among both groups (Japanese-American and Caucasian) were "remaining in good health until close to death" and "being able to make choices about things that affect how I age" (Phelan et al., 2004).

\section{Research Purpose}

This four stage interpretive descriptive study examined the beliefs, values, lifestyles and health status of adults at least 75 years old who identified themselves as healthy. The central questions of the study are what attitudes and perceptions contribute to thriving in older adulthood and what can we learn from thriving older adults about structuring health care encounters to facilitate further thriving?

\section{Methods}

After receiving approval for the study from the Institutional Review Board, four Stage 1 focus groups with staff were held at four distinct health-related sites in the San Francisco Bay Area. The sites were two medical offices, one 99 bed skilled nursing facility (SNF), and one site that contained senior housing and assisted living for $150+$ residents. The sites provided access to older adults living across the spectrum of ability and function. The initial focus groups were incorporated as the final portion of a scheduled staff meeting at each site. Each focus group lasted between 30 to 45 minutes and was recorded and later transcribed.

The purpose of the Stage 1 focus groups was to introduce the researcher and the project, to discuss health among older adults, and to request referral of adults aged 75 years and older who identify themselves as healthy. Researcher contact cards were distributed for questions or referrals and flyers advertising the study were posted in prominent places at each site for 60 days.

Stage 2 consisted of three full-day participantobservation sessions at each site to gather data about the site, staff, and clients. Sessions were scheduled across various work shifts and days of the week. These sessions made the researcher visible, and led to numerous referrals of older adults for interview (Stage 3).

A total of 26 older adults contacted the researcher about the study. Each was informed that participation would consist of a recorded interview at the older adult's place of residence and chart review at the health-related site of care to gather a list of diagnoses, medications, and demographic data. Of the 26 respondents, 18 $(69.23 \%)$ agreed to participate (Stage 3). Of the 8 respondents who did not continue to participate, 3 cited mere curiosity as their reason 
for calling and 5 responded to the flyer in hopes of obtaining information about either staying healthy, getting health care, or accessing senior services.

Among the 18 participants, 11 lived independently in the community, 5 resided in assisted living, and 2 were residents in a SNF. The mean age of participants was 82.8 years; 11 were female; 7 were male. Seventeen of the 18 participants were identified by staff as examples of healthy older adults who would be models for successful aging. The one participant that staff did not perceive as an example of healthy aging was referred as an example of the opposite of what was desired for the study. She rated her health as poor, and was included as a negative case. An additional three participants reported their health as fair $(\mathrm{N}=2)$ or poor $(\mathrm{N}=1)$, yet were perceived to be in good or excellent health by staff. They were included to examine the discrepancy in perceptions. The 18 interviews ranged from 81-118 minutes, with an average length of 95 minutes. Table 1 presents the initial interview guide. As is true in qualitative studies, this guide was used to structure all interviews, however, follow-up questions and prompts were individualized based on the responses offered.

At the completion of the older adult interviews (Stage 3), a group interview (Stage 4) consisting of 8 staff members who were the most actively involved in recruitment of older adults was held at a meeting room in a local café. Two staff members from each of the four sites participated in the interview. The one-hour interview was recorded and transcribed for analysis. At the meeting, each participant was asked to describe healthy older adults that they see in their work setting, discuss how health is evaluated in older adults, and identify what activities promote health in aging. Key statements made in the Stage 1 focus groups were reported to the Stage 4 group for further discussion and clarification. Observations from Stage 2 were also presented to the Stage 4 group.

Table 1

\section{Initial Interview Guide}

- Would you rate your current state of health as excellent, good, fair, or poor?

- Why did you select this rating?

- What does it mean to be healthy as you age?

- What activities do you engage in to maintain or improve your health?

- How does your living environment contribute to your health?

- What suggestions do you have for others about health in aging?

- What suggestions do you have for health care providers about health in aging?

\section{Data Analysis}

Concurrent data collection and analysis enabled the researcher to explore emerging themes in subsequent stages and interviews. Transcripts were read and reread to identify and code themes that were inherent in the participants' experiences as they reported it. Triangulation of data occurred among stages. For example, staff beliefs (expressed in Stage 1) were monitored for accuracy in Stage 2. Older adult comments about health care were compared with comments and observations from the previous stages. Finally, themes derived from the initial stage, as well as observations at the sites, and comments about health and health care made by older adults were presented for discussion with key staff members in Stage 4.

\section{Results}

The intent of this study was to examine health beliefs, attitudes, and behaviors of older adults who perceive themselves as healthy and to look at health encounters and health settings in which older adults receive care. The original analysis of the data identified engagement as a central 
component of healthy aging. Data were consistent with the findings of Strawbridge et al. (2002), as a list of physiological, cognitive, or functional impairments was not predictive of who would self-evaluate as healthy. However, older adults who perceived themselves as healthy were more actively engaged in their lives and surroundings than those with lower rated self-health (Van Leuven, 2010). The results support the belief that social engagement is an important aspect of perceived health and successful aging, a finding consistent with the original work of Pressey \& Simcoe (1950).

Upon further investigation of the data, an unanticipated finding was that all participants who self-identified as healthy $(\mathrm{N}=14)$ had in place some form of advance directive which indicated their end-of-life wishes. These advance directives (AD) took the form of living wills (9/14; 64.29\%), Durable Power of Attorney for Health Care [DPAH] $(7 / 14 ; 50 \%)$, Do Not Resuscitate (DNR) forms (6/14; $42.86 \%$ ), and Preferred Intensity of Care (PIC) documentation $(2 / 14 ; 14.29 \%)$. In contrast, participants who self-identified as fair or poor health $(\mathrm{N}=4)$ did not have advance directives $(0 / 4 ; 0 \%)$. Table 2 summarizes the findings of the study and provides information on each participant.

Table 2.

Characteristics of Older Adult Participants

\begin{tabular}{|c|c|c|c|c|c|}
\hline Participant \# & $\begin{array}{c}\text { Residence } \\
\text { Type }\end{array}$ & $\begin{array}{c}\text { Demographics } \\
\text { (Age, Gender, } \\
\text { Marital Status) } \\
\end{array}$ & Diagnoses & Inclusion Status & $\begin{array}{l}\text { Advanced } \\
\text { Directives }\end{array}$ \\
\hline 1 & Community & 81 F Married & $\begin{array}{l}\text { - Prior bilateral mastectomy for } \\
\text { breast cancer } \\
\text { - Hypertension } \\
\text { - Hypothyroidism } \\
\text { - Osteoarthritis }\end{array}$ & $\begin{array}{l}\text { Self-report of } \\
\text { healthy }\end{array}$ & $\begin{array}{l}\text { DNR } \\
\text { DPAH }\end{array}$ \\
\hline 2 & Community & 83 M Married & $\begin{array}{l}\text { - Type } 2 \text { Diabetes } \\
\text { - Hypertension } \\
\text { - Irritable bowel syndrome } \\
\text { - Spinal stenosis } \\
\text { - Benign prostatic hypertrophy }\end{array}$ & $\begin{array}{l}\text { Self-report of } \\
\text { healthy }\end{array}$ & $\begin{array}{l}\text { DNR } \\
\text { DPAH }\end{array}$ \\
\hline 3 & Community & 84 F Widowed & $\begin{array}{l}\text { - Hypertension } \\
\text { - Anxiety } \\
\text { - Temporal Arteritis } \\
\text { - Osteoporosis }\end{array}$ & $\begin{array}{l}\text { Self-report of } \\
\text { healthy }\end{array}$ & LW \\
\hline 4 & Community & 85 M Widowed & $\begin{array}{l}\text { - Hypertension } \\
\text { - } \text { Dyslipidemia } \\
\text { - Prostethic aortic valve on } \\
\text { - } \text { warfarin } \\
\text { - Osteoarthritis } \\
\text { - Spinal stenosis }\end{array}$ & $\begin{array}{l}\text { Self-report of } \\
\text { healthy }\end{array}$ & $\begin{array}{l}\text { LW } \\
\text { DPAH }\end{array}$ \\
\hline 5 & SNF & 92 F Widowed & $\begin{array}{l}\text { - } \text { Type } 2 \text { Diabetes } \\
\text { Peripheral Vascular Disease } \\
\text { - Hypertension } \\
\text { - Early Alzheimer's }\end{array}$ & $\begin{array}{l}\text { Self-report of } \\
\text { healthy }\end{array}$ & $\begin{array}{l}\text { DNR } \\
\text { PIC }\end{array}$ \\
\hline 6 & Community & 90 F Widowed & $\begin{array}{l}\text { - } \text { Type } 2 \text { Diabetes } \\
\text { - Hypertension } \\
\text { - Dyslipidemia } \\
\text { - Osteoarthritis }\end{array}$ & $\begin{array}{l}\text { Self-report of } \\
\text { healthy }\end{array}$ & LW \\
\hline
\end{tabular}




\begin{tabular}{|c|c|c|c|c|c|}
\hline 7 & Community & 78 M Married & $\begin{array}{ll}\text { - } & \text { Type } 2 \text { Diabetes } \\
\text { - } & \text { Hypertension } \\
\text { - } & \text { Dyslipidemia } \\
\text { - } & \text { Multiple TIAs }\end{array}$ & $\begin{array}{l}\text { Self-report of } \\
\text { healthy }\end{array}$ & $\begin{array}{l}\text { LW } \\
\text { DPAH }\end{array}$ \\
\hline 8 & Asst. Living & 83 F Widowed & $\begin{array}{l}\text { - Congestive Heart Failure } \\
\text { - Hypertension } \\
\text { - Osteoarthritis } \\
\text { - Stress Incontinence }\end{array}$ & $\begin{array}{l}\text { Self-report of } \\
\text { healthy }\end{array}$ & $\begin{array}{l}\text { DNR } \\
\text { LW } \\
\text { DPAH }\end{array}$ \\
\hline 9 & Asst. Living & 79 F Single & $\begin{array}{l}\text { - Hypertension } \\
\text { - Atrial Fibrillation } \\
\text { - Severe kyphoscoliosis }\end{array}$ & $\begin{array}{l}\text { Self-report of } \\
\text { healthy }\end{array}$ & $\begin{array}{l}\text { LW } \\
\text { DPAH }\end{array}$ \\
\hline 10 & Asst. Living & $81 \mathrm{M}$ Widowed & $\begin{array}{l}\text { - Hypertension } \\
\text { - Colostomy due to colectomy for } \\
\text { cancer treatment }\end{array}$ & $\begin{array}{l}\text { Self-report of } \\
\text { healthy }\end{array}$ & DNR \\
\hline 11 & SNF & 90 M Single & $\begin{array}{l}\text { - Prior CVA with hemiplegia } \\
\text { - Peripheral Vascular Disease } \\
\text { - Hypertension } \\
\text { - } \text { Dyslipidemia }\end{array}$ & $\begin{array}{l}\text { Self-report of } \\
\text { healthy }\end{array}$ & $\begin{array}{l}\text { DNR } \\
\text { PIC }\end{array}$ \\
\hline 12 & Asst. Living & 80 M Single & $\begin{array}{l}\text { - Coronary Artery Disease } \\
\text { - History of MI } \\
\text { - Hypertension }\end{array}$ & $\begin{array}{l}\text { Self-report of } \\
\text { healthy }\end{array}$ & $\begin{array}{l}\text { LW } \\
\text { DPAH }\end{array}$ \\
\hline 13 & Community & $81 \mathrm{~F}$ Married & $\begin{array}{l}\text { - } \text { Type } 2 \text { Diabetes } \\
\text { - Hypertension } \\
\text { - } \text { Osteoarthritis }\end{array}$ & $\begin{array}{l}\text { Self-report of } \\
\text { healthy }\end{array}$ & LW \\
\hline 14 & Community & 79 F Widowed & $\begin{array}{l}\text { - Degenerative Joint Disease } \\
\text { - Hypertension } \\
\text { - Atrial Fibrillation }\end{array}$ & $\begin{array}{l}\text { Self-report of } \\
\text { healthy }\end{array}$ & LW \\
\hline 15 & Asst. Living & 78 F Single & $\begin{array}{l}\text { - Post polio syndrome } \\
\text { - Prior mastectomy for breast } \\
\text { cancer } \\
\text { - Osteoartritis } \\
\text { - Hypothyroidism }\end{array}$ & $\begin{array}{l}\text { - Self-report of } \\
\text { poor health } \\
\text { - Staff evaluate } \\
\text { as poor health }\end{array}$ & None \\
\hline 16 & Community & 83 F Married & $\begin{array}{l}\text { - Irritable bowel syndrome } \\
\text { - Emphysema } \\
\text { - Anxiety }\end{array}$ & $\begin{array}{l}\text { - Self-report of } \\
\text { poor health } \\
\text { - Staff evaluate } \\
\text { as good health }\end{array}$ & None \\
\hline 17 & Community & 85 M Married & $\begin{array}{l}\text { - Hypertension } \\
\text { - History of MI } \\
\text { - Dyslipidemia } \\
\text { - Macular Degenration } \\
\text { - Pacemaker due to AV block }\end{array}$ & $\begin{array}{l}\text { - Self-report of } \\
\text { fair health } \\
\text { - Staff evaluate } \\
\text { as good health }\end{array}$ & None \\
\hline 18 & Community & 78 F Married & $\begin{array}{l}\text { - Prior lumpectomy for breast } \\
\text { cancer } \\
\text { - Hypertension } \\
\text { - Osteoarthritis }\end{array}$ & $\begin{array}{l}\text { - Self-report of } \\
\text { fair health } \\
\text { - Staff evaluate } \\
\text { as good health }\end{array}$ & None \\
\hline
\end{tabular}

Older adults who self-evaluated as healthy $(\mathrm{N}=14)$ successfully negotiated change brought about by illness, stress, or loss of abilities or loved ones by engaging with others. This group brushed off changes with statements such as, "these things happen" and "it's part of the ride," while continuing to be involved with family, friends, interest groups, and their community. 
One participant described this approach as "just rolling with it." In contrast, the small group $(\mathrm{N}=4)$ that did not self-evaluate as healthy anticipated ongoing negative events with comments such as, "It's terrible to get old and then it just gets worse," while contracting into a smaller circle of contacts. Thus it appears that self-perceived healthy older adults have more resilience in the face of internal and external threats than those with lower self-rated health.

A similar pattern emerged in their approach to end-of-life issues. The self-perceived healthy group was open to discussing the tenuous nature of ongoing longevity. Participant \#4, an 85-yearold widowed man with spinal stenosis, hypertension, dyslipidemia, and a mechanical aortic valve stated:

At my age, everyday on this side of the sod is a good day, I do everything I can to stay healthy. But you can't live with blinders on. You have to be prepared that you might not live much longer.

This man acted on his words by completing a living will, durable power of attorney for health care, and by engaging in conversations about his wishes with his providers and his family. Although he was prepared for his death, he was also very proactive about maintaining his health by exercising six days per week, eating a low salt, low sugar, high fiber diet, maintaining his immunizations, carefully monitoring his blood work, visiting his provider monthly, and being actively engaged in his community through extensive volunteer work which included running a community food bank.

Participant \#5, a 92-year-old widow with Type 2 diabetes moved to a SNF after a brief hospitalization for cellulitis associated with chronic venous stasis. Originally her admission was intended to be short-termed, but her family was relieved to have her housed in an institution due to her increasing forgetfulness. Although she admitted that a SNF was "the last place" she wanted to be, her actions belied her feelings. As a retired nurse she felt best helping out the staff. She fed her roommate, served coffee, socialized with residents who were bedbound, folded linen, and made beds for the staff. "I do the best I can and take each day as it comes. As long as the good Lord is willing, I'll keep doing my best." When talking about her placement at the SNF, she showed no bitterness:

They did what they thought was best. But I'm not going to curl up and die over it. I like the people here. It worked out. This is my home now and this is where I want to be until I die.

Her outgoing nature and ongoing work often led visitors to conclude that she was a staff member. Each day she made 10 laps around the SNF after each meal because she believed that "exercise is good for the heart and soul." She had in place a DNR and a PIC form that requested that care be focused on comfort, no transfer back to the hospital, and no artificial nutrition.

In contrast, those who perceived themselves to be in fair or poor health eschewed conversation and planning about end-of-life. For example, Participant \#15, a 78-year-old female with postpolio syndrome and a history of breast cancer, rated her health as poor. However, when discussing her poor health and longevity, she stated, "I don't even want to think about it. I have a hard enough time dealing with now. I can't plan for what might happen." Further prompts were unable to get her to return to this subject. For this woman, life was about dealing with chronic pain and fatigue. Her life was focused on back pain related to use of a crutch, complicated by thoracic vertebral fractures that occurred after her mastectomy. Her day revolved around taking medications, visits to health care providers, and resting. "Life is hell," she described. She had a good relationship with her primary care provider, but felt nothing could really be done for her. Similarly, Participant \#18, a 78-year-old female with hypertension and osteoarthritis was three years post lumpectomy for breast cancer and currently rated her health as fair. She described her experience:

I suppose I'll live a long life because my mother did. So I guess that means I'll have a lot of pain and misery. But that's not 
something I want to think about it. I don't think it's appropriate to even talk about it.

Since neither of these women had enacted an advanced directive, by default they would receive aggressive care in the event of decline in status or cardiopulmonary arrest. Both described their current situation in extremely negative terms, yet lack of advance directives would set in motion care that would sustain a negative experience. In contrast, those who reported being content with their health status had enacted directives to limit life-sustaining treatment.

\section{Discussion}

On the national level, advance care planning is increasingly controversial. Beginning in the 1960s cardiopulmonary resuscitation (CPR) became a requirement for all hospitalized patients in the event of a cardiac arrest. This change was brought on by the increasing use of technology and positive experience with initial use of CPR (Brauner, 2010; Perkins, 2007). However, by 1974 sentiments about CPR had begun to change due to mounting numbers of survivors with anoxic brain damage and disappointing experience with CPR in patients who were clearly dying of chronic cardiovascular disease and cancer. This resulted in the institution of "do not resuscitate" (DNR) orders and thereby heralded in the era of advance directives (Standards, 1974). High profile cases involving persistent vegetative state, and questions regarding withdrawal of nutritional or life support therapies (e.g., Terri Sciavo, Nancy Cruzan) further pushed the discussion (Green \& Wikler, 2009). The result was the Patient Self-Determination Act (PSDA) of 1991 that required hospitals, skilled nursing facilities, and home health services to inquire, at admission, if patients have in place advance directives, to provide patients with a written summary of their rights in regard to healthrelated decision-making rights, and to provide education to staff and the community about advance directives. Furthermore, the Joint Commission on Accreditation of Healthcare Organizations (JCAHO) requires that hospitals document evidence of all known advance directives and provide information on advance care planning to all patients (Ramsaroop, Reid, Adelman, 2007). In spite of these legal and regulatory requirements, estimates of completed advance directives in the population of U.S. citizens range from 5-15\% (Ramsaroop, Reid, Adelman, 2007).

Schickedanz et al. (2009) when examining reasons for not participating in advance care planning among 205 general medicine patients over 50 years of age who were able to converse in English or Spanish at an urban teaching facility found that $84 \%$ of all participants believed that advance care planning was irrelevant. The most cited rationale for irrelevance was being too healthy. Of note, more than two-thirds of the participants self-rated their health status as fair to poor and many had prior critical care stays while hospitalized (Schickedanz et al., 2009). Other reasons for not participating in advance care planning included personal barriers such as work or family issues $(53 \%)$, relationship concerns $(46 \%)$, not having enough information about personal health or healthcare choices $(36 \%)$, limited time during health encounters $(29 \%)$, and problems with advance directives forms or the process in general (29\%) (Schickedanz et al., 2009).

In the population that Schickedanz et al. (2009) studied, participants felt they were too healthy for advance directives, yet predominantly selfrated health as fair to poor. In this study, those who perceived themselves to be healthy were the only ones with advance directives in place. There was a striking difference between the mean age of participants in these studies, with participants in Schickedanz et al. (2009) being on average 61.0 years of age versus 82.8 years in the present study. This mean difference of 21.8 years may account for a different view on the relevance of advance directives.

\section{Summary of the Findings \& Limitations}

This is a qualitative study with a small sample size $(\mathrm{N}=18)$ focused on older adults who selfidentify as healthy. Social engagement was found to be a key difference between the healthy and lower-rated health status participants in this sample (Van Leuven, 2010). On secondary 
analysis of data, a surprising association between presence of advance directives and selfperceived health was identified. The selfdescribed healthy group approached advanced care planning as part of health promotion. In contrast, those who evaluated their health as fair or poor perceived advanced care planning as something to be avoided. Planning for end-oflife may be a form of ongoing engagement as it requires dialogue with health care providers, and thoughtful consideration of experiences and wishes. It may also be a manifestation of successful aging in that death is recognized as the culmination of a good life rather than something to be feared. Further study with a large sample is recommended to determine if there is a relationship between expressed end-oflife wishes, self-identified health, and engagement.

\section{Implications}

The message from healthy participants in this study is to simultaneously embrace healthy living while planning for end-of-life. Incorporating the topic of advanced directives into comprehensive exams, annual physicals, and new patient intakes for all adults, and regularly updating the information, would incorporate the spirit of their message and normalize the discussion of advance care planning. These visits contain a review of social history which includes discussion of lifestyle activities, such as exercise, diet, smoking status, and substance use. In this context, it is appropriate to inquire if any advance planning has been done in relation to designating a health care proxy or if there are any wishes to be considered in the event of a change in health status that might make the individual unable to make his/her own decisions. In this manner, we have made the topic relevant even for young, healthy individuals and begun a dialogue with a patient that conveys interest and caring.

Shalowitz \& Silveira (2010) note that advance directives are generic and often impersonal. They recommend advanced care planning with a provider who knows the patient, has good communication skills, and common sense. Providers who possess these attributes, and are well-versed in health promotion, are ideally situated to be involved in end-of-life planning.

\section{References}

Baltes, P.B. (1997). On the incomplete architecture of human ontogeny. American Psychologist, 52, 366380.

Brauner, D.J., (2010). Reconsidering default medicine. Journal of the American Geriatric Society, 58, 599-601.

Depp C.A. \& Jeste, D.V. (2009). Definitions and predictors of successful aging: A comprehensive review of larger quantitative studies. American Journal of Geriatric Psychiatry, 14, 6-20.

Fried, T. R., Bullock, K., Iannone, L., \& O’Leary, J.R. (2009). Understanding advance care planning as a process of health behavior change. Journal of the American Geriatric Society 57(9), 1547-1555.

Fries, J.F. (2002). Successful aging - an emerging paradigm of gerontology. Clinics in Geriatric Medicine, 18, 371-382.

Green, M.B. \& Wikler, D. (2009). Brain death and personal identity. In J.P. Lizza (Ed.) Defining the beginning and end of life (pp. 507-532). Baltimore: Johns Hopkins University Press.

Lupien, S.J. \& Wan, N. (2004). Successful ageing: From cell to self. Philosophical Transactions of the Royal Society of London B: Biological Sciences, 359, 1413-1426. doi:10.1098/rstb.2004.1516.

McLaughlin, S.J., Connell, C.M., Heeringa, S.G., Li, L.W., \& Roberts, J.S. (2010). Successful aging in the United States: Prevalence estimates from a national sample of older adults. The Journals of Gerontology Series B, 65B(2), 216-226. doi: 10.1093/geronb/gbp101

Perkins, H.S. (2007). Controlling death: The false promise of advance directives. Annals of Internal Medicine, 147(1), 51-57.

Phelan, E.A., Anderson, L.A., LaCroix, A.Z., \& Larson, E.B. (2004). Older adults" views of "successful aging" - How do they compare with researchers definitions? Journal of the American Geriatric Society 52(2), 211-216. 
Ramsaroop, S.D., Reid, M.C., \& Adelman, R.D. (2007). Completing an advance directive in the primary care setting: What do we need for success? Journal of the American Geriatric Society 55(2), $277-$ 283.

Rowe, J.W. \& Kahn, R.L. (1987). Human aging: Usual and successful. Science, 237, 143-149.

Rowe, J.W. \& Kahn, R.L. (1997). Successful aging. The Gerontologist, 37(4), 433-440.

Schickedanz, A.D., Schillinger, D, Landefeld, C.S., Knight, S.J., Williams, B.A., \& Sudore, R.L. (2009). A clinical framework for improving the advance care planning process: Start with patients' selfidentified barriers. Journal of the American Geriatric Society, 57(1), 31-39. doi:10.1111/j.15325415.2008.02093.x.

Schulz, R. \& HeckHausen, J. (1996). A life span model of successful aging. American Psychologist, 51, 702-714.

Shalowitz, D.I. \& Silveira, M.J. (2010). Building a better advance directive: Next steps. American Journal of Bioethics, 10(4), 34-36.

Standards for cardiopulmonary resuscitation (CPR) and emergency cardiac care: V: Medicolegal considerations and recommendations. Journal of the American Medical Association, 227, 864868.

Van Leuven, K.A. (2010). Health practices of older adults in good health: Engagement is the key. Journal of Gerontological Nursing, 36(6), doi:10.3928/00989134-20091110-99

von Faber, Bootsma-van der Wiel, A, van Exel, E., Gussekloo, J., Lagaay, A.M. van Dongen, E., Knook, D.L., van der Geest, S., Westendoorp, R.G. (2001). Successful aging in the oldest old: Who can be characterized as successfully aging? Archives of Internal Medicine, 161(22), 2694-700.

\author{
Author Information \\ Karen Van Leuven, PhD, FNP* \\ Associate Professor \\ Co-Director of Advanced Practice Program \\ University of San Francisco \\ 2130 Fulton Street \\ San Francisco, CA 94117 \\ Telephone: (415) 422-6594 \\ Fax: (415) 422-5618 \\ Email: kavanleuven@usfca.edu \\ * corresponding author
}

